\title{
Ecological Potential of Osmotic Power Generation by Pressure Retarded Osmosis in Ontario, Canada
}

\author{
Bassel A. Abdelkader, Mostafa H. Sharqawy* \\ School of Engineering, College of Engineering and Physical Sciences, \\ University of Guelph, Guelph, Ontario N1G 2W1, Canada \\ babdelka@uoguelph.ca; melsharq@uoguelph.ca
}

\begin{abstract}
Rural and remote communities in Northern Ontario rely on diesel generators as their main source of power. Diesel-generated electricity has a large carbon footprint and it is not an economically feasible source of energy, thus there is a vast interest in using alternative energy sources. Osmotic power is considered one of the promising techniques of renewable energy generation. The technical and ecological potential of osmotic power plants in Ontario is investigated in this study along with an overview of the costs involved. The estimated technical power production from Ontario rivers is around $3.2 \mathrm{GW}$, whereas, the ecological power production is estimated to be about 473.3 MW. The total membrane cost is estimated to be $\$ 2,000$ for each $\mathrm{kW}$ installed within a few years, which represents about $70 \%$ of the total plant capital cost. According to the findings of this study, osmotic power systems represent an economically feasible alternative to other clean sources of renewable energy such as wind and solar systems.
\end{abstract}

Keywords: Osmotic power; Pressure retarded osmosis; Potential analysis; Power density; Renewable energy

\section{Introduction}

Renewable energy technologies have attracted the scientific society to reduce greenhouse gas emissions from fossilfueled power plants. Pressure retarded osmosis (PRO) has a great potential of energy production, utilizing the osmotic pressure between two solutions of different salinities separated by a semi-permeable membrane. The water flows through the membrane from the lower to higher salinity due to that osmotic pressure difference [1]-[3]. The energy generated by depressurizing the draw solution (the high salinity solution which is diluted) using a hydro turbine, increases with the osmotic pressure difference between the two solutions [4]. A major advantage of PRO systems is the ability to generate a constant power supply for base loads when compared to other renewable energy technologies, such as solar and wind systems where the power generated has low availability factor [5]-[9].

The global theoretical potential of PRO is $3.2 \mathrm{TW}$ which is limited by the world's rivers water discharge [10]. In practice, it is impossible to achieve the theoretical potential due to the technical constraints of the energy conversion process in the osmotic power plants. Thus, the technical potential considers the pressure drop, pump and turbine efficiencies as sources of energy loss. The technical potential is calculated using all the rivers water discharge, however, the amount of water that can be extracted is limited by the ecological stability. Therefore, the ecological stability is a subset of the technical potential taking into consideration the ecological restrictions. The global technical potential of PRO is $647 \mathrm{GW}$, whereas, the global ecological potential of PRO is $65 \mathrm{GW}$ as shown in Table 1 [10].

Table 1: Theoretical, technical, and ecological potential of global osmotic power [10].

\begin{tabular}{lccc}
\hline Continent & $\begin{array}{c}\text { Theoretical potential } \\
{[\text { GW] }}\end{array}$ & $\begin{array}{c}\text { Technical potential } \\
{[\text { GW] }}\end{array}$ & $\begin{array}{c}\text { Ecological potential } \\
{[\text { GW] }}\end{array}$ \\
\hline Asia & 1015 & 208 & 21 \\
Africa & 307 & 63 & 6 \\
North America & 479 & 98 & 10 \\
South America & 969 & 199 & 20 \\
Europe & 241 & 49 & 5 \\
Australia & 147 & 30 & 3 \\
\hline
\end{tabular}


The potential of the PRO system was investigated across different continents as well as focusing on particular countries. For instance, the technical potential in Europe is estimated to be $395 \mathrm{TWh} /$ year whereas, the ecological potential is estimated to be $39 \mathrm{TWh} /$ year. On the other hand, in North America the technical potential is estimated to be $785 \mathrm{TWh} /$ year whereas, the ecological potential is estimated to be $79 \mathrm{TWh} / \mathrm{year}$ [10]. On a smaller scale, a country like Norway has a technical potential of around $12 \mathrm{TWh} /$ year, which represents one tenth of the current power consumption in the country [11].

The cost of the osmotic power production was compared to other renewable and non-renewable energy technologies [12]. The osmotic power production cost was estimated to be in the range of 50-100 €/MWh, whereas the energy cost of solar, biomass, hydro dam, and wind (onshore and offshore) were 160, 88, 85, 90, $115 € / \mathrm{MWh}$ respectively [12]. The cost of energy generated from the PRO system is estimated to be in the range of $\$ 0.09$ to $\$ 0.11$ per $\mathrm{kWh}$. These numbers are expected to be reduced to be between $\$ 0.05-\$ 0.06$ per $\mathrm{kWh}$ if subsidy programs and other government incentives are applied [13]. Additionally, capital amortization would amount to more than $60 \%$ of the total energy cost.

According to the Institut de recherche d'Hydro-Québec, the ecological potential for osmotic power in Canada is 4.2 $\mathrm{GW}$, which is calculated using $15 \%$ of the average flow of the rivers. In the remote regions of Canada, diesel engines are the main source of energy which are not considered sustainable. For example, in the remote regions of Quebec, the potential of the osmotic power was estimated to be in the range of $0.9-10.5 \mathrm{TWh} /$ year, which is sufficient to meet the energy demand in those remote regions [14]. However, there was a clear gap present in the literature regarding the potential of osmotic power in other major Canadian provinces such as Ontario. The province of Ontario has many major rivers and would thus has a great potential of osmotic power production. Therefore, the objective of this paper is to investigate the technical and ecological potential of osmotic power plants in Ontario.

\section{PRO Potential in Ontario}

Although most of Ontario is supplied by a well-developed electrical network, there are more than 31 remote communities in the Northern and Western regions as shown in Figure 1 [15]. These communities rely on locally supplied micro grids (mostly diesel engines) where the electricity cost ranges from $\$ 0.4 / \mathrm{kWh}$ to $\$ 1.2 / \mathrm{kWh}$ and produce large amounts of carbon emissions [16]. Therefore, a cleaner and affordable renewable energy system is favorable for these remote communities. Mean discharge rate for different rivers in Ontario are presneted in Table 1. Due to the high total river discharge rate of 4510 $\mathrm{m}^{3} / \mathrm{s}$, there is a great potential for osmotic power plants at these river mouths and James and Hudson bays. Osmotic power generation has many advantages compared to other renewable energy systems, predominately its production stability. This is due to changes in concentration being insignificant when compared to the major fluctuations in wind speed, river speed and solar radiations present in other renewable systems. PRO systems require an estimated $0.043 \mathrm{~km}^{2}$ for every MW, which is almost equivalent to the area required by solar systems, 6 and 8 times smaller than that of wind systems and hydroelectricity (including reservoirs), respectively [17].

The amount of useful power available from the permeate depressurization is calculated using a one-dimensional model for a finite size exchanger as given by Eq. (1) [18]. This model assumes that the maximum power occurs at $\Delta P=\Delta \pi / 2$, and water permeability coefficient is constant. The concentration polarization and pressure drop effects are neglected. The osmotic pressure is calculated using the correlation given by [19].

$$
\dot{W}_{\max }=\frac{\eta \dot{m}_{f, i n} \Delta \pi_{\max }}{\rho_{d}}\left(\theta_{d}-2 \sqrt{\theta_{d} \theta_{f}}+\theta_{f}\right)
$$

where

$$
\begin{aligned}
\Delta \pi_{\max } & =\pi_{d, i n}-\pi_{f, i n} \\
\theta_{d} & =\frac{\pi_{d, i n}}{\Delta \pi_{\max }} \\
\theta_{f} & =\frac{\pi_{f, i n}}{\Delta \pi_{\max }}
\end{aligned}
$$


and $\eta$ is the combined turbine and generator efficiency assumed to be $80 \% . \dot{m}_{f, \text { in }}$ is the mass flow rate of the inlet feed water coming from the rivers.

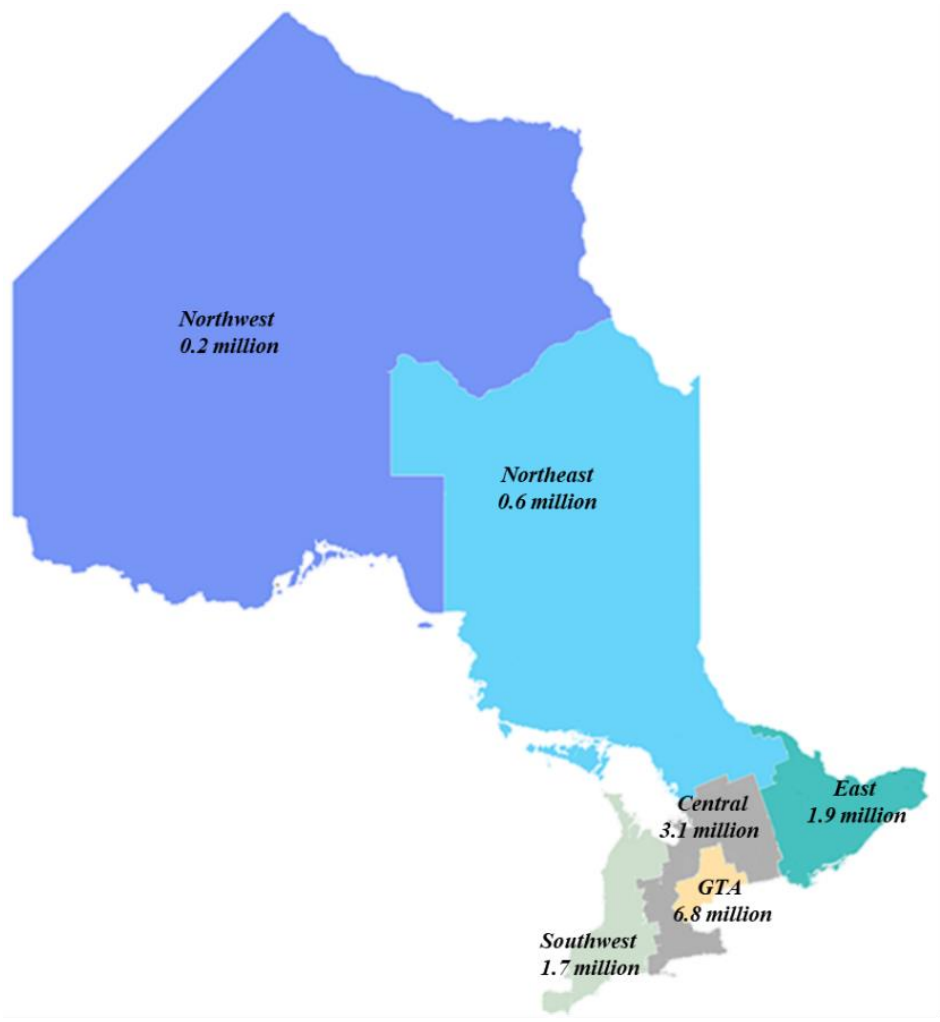

Fig. 1: Population of Ontario regions [15].

Table 2: Mean discharge rate for different rivers in Ontario [20].

\begin{tabular}{lcc}
\hline River & Drainage Mouth & Mean discharge $\mathbf{~ m}^{\mathbf{3}} \mathbf{s}$ \\
\hline Severn & Hudson Bay & 300 \\
Winisk & Hudson Bay & 694 \\
Ekwan & James Bay & 100 \\
Attawapiskat & James Bay & 626 \\
Albany & James Bay & 1420 \\
Moose & James Bay & 1370 \\
\hline
\end{tabular}

\section{Results and Discussion}

Hudson Bay has an area of 1.4 million $\mathrm{km}^{2}$ and average salinity of $32 \mathrm{~g} / \mathrm{kg}$, where 14 major rivers discharge, 7 of which are in the Northern and Western regions of Ontario as shown in Figure 2. The average water salinity of these rivers is $1.5 \%$. During the winter, the average ice thickness is $173 \mathrm{~cm}$. Although the rivers are ice-covered annually for 6 months, water continues to flow under the ice [21]. There are very few power plants present in the Northern and Western regions of Ontario, on the other hand, there are 7 major rivers present in those regions. For these reasons, osmotic power plants are the optimal choice for power production in Northern and Western regions of Ontario. The technical and ecological osmotic power potential in Ontario is shown in Table 3. The estimated technical power production from Ontario rivers is $3.15 \mathrm{GW}$, 
considering available membrane performance and equipment efficiencies. Whereas, the ecological power production is 473.3 MW assuming only $15 \%$ of the river flow rate.

Table 3: The estimated technical and ecological Osmotic Power Potential for different rivers in Ontario.

\begin{tabular}{lcc}
\hline River & Technical potential & Ecological potential \\
\hline Severn & $209.9 \mathrm{MW}$ & $31.5 \mathrm{MW}$ \\
Winisk & $485.5 \mathrm{MW}$ & $72.8 \mathrm{MW}$ \\
Ekwan & $69.95 \mathrm{MW}$ & $10.5 \mathrm{MW}$ \\
Attawapiskat & $437.9 \mathrm{MW}$ & $65.7 \mathrm{MW}$ \\
Albany & $993.3 \mathrm{MW}$ & $149.0 \mathrm{MW}$ \\
Moose & $958.3 \mathrm{MW}$ & $143.8 \mathrm{MW}$ \\
\hline Total & $\mathbf{3 1 5 5} \mathbf{M W}$ & $\mathbf{4 7 3 . 3} \mathbf{M W}$ \\
\hline
\end{tabular}

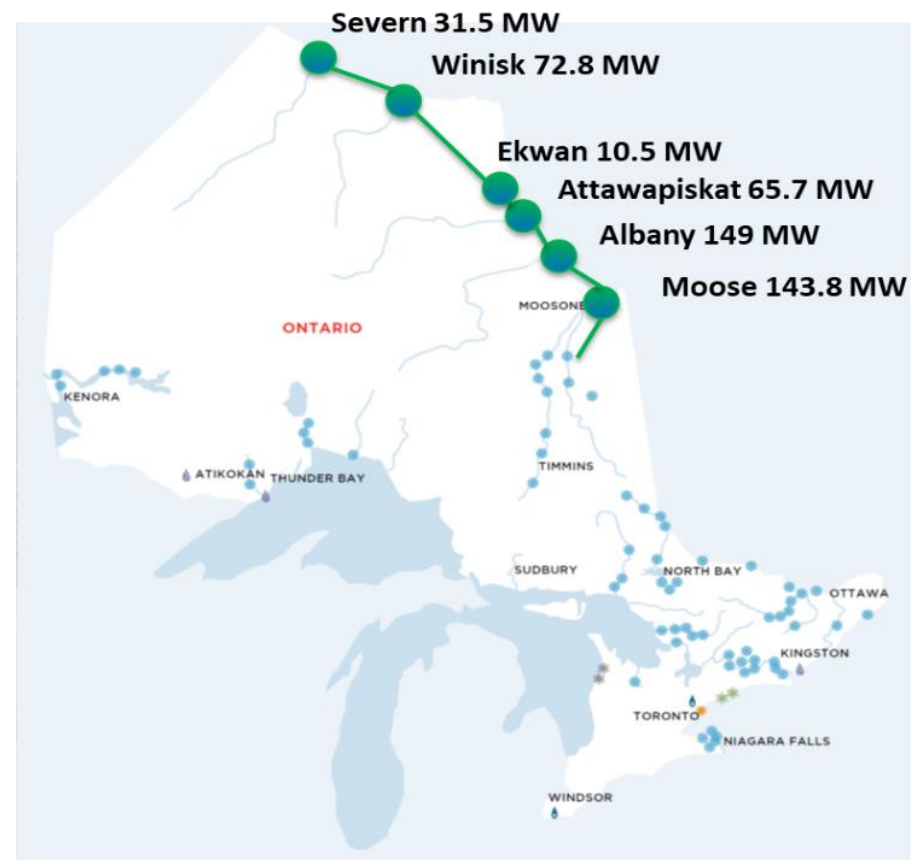

Fig. 2: Estimated osmotic power potential of remote communities that rely on locally supplied micro grids in Ontario.

\section{The Economics of PRO}

The commercial utilization of osmotic power is influenced by the energy cost, which depends on capital and operational expenses. These expenses can be broken down into the cost of the pressurization of the draw solution, streams pre-treatment and membrane replacement. Intake and outfall systems, pre-treatment facilities, and equipment all combined account for about $30 \%$ of the total installation cost. The cost of the membrane accounts for about $70 \%$ of the capital cost. Therefore $70 \%$ of the capital cost depends on the unit price of the membrane $\left(\$ / \mathrm{m}^{2}\right)$ and its power density $\left(\mathrm{W} / \mathrm{m}^{2}\right)$ as given by Eq. (5). For a membrane cost of $\$ 10$ per $\mathrm{m}^{2}$ and a power density of $5 \mathrm{~W} / \mathrm{m}^{2}$, the cost is $\$ 2,000$ for each $\mathrm{kW}$ installed as shown in Fig. 3. The current average membrane price is $\$ 40$ per $\mathrm{m}^{2}$, moreover, the average membrane price has decreased significantly over time and will continue to decrease over the next few years. The current membrane power density is $5 \mathrm{~W} / \mathrm{m}^{2}$; but within a few years it will be possible to produce membranes with a power density of $15 \mathrm{~W} / \mathrm{m}^{2}$ [5]. 


$$
70 \% \text { of capital cost }=\frac{\text { Membrane cost }\left[\$ / \mathrm{m}^{2}\right]}{\text { Power density }\left[\mathrm{W} / \mathrm{m}^{2}\right]}
$$

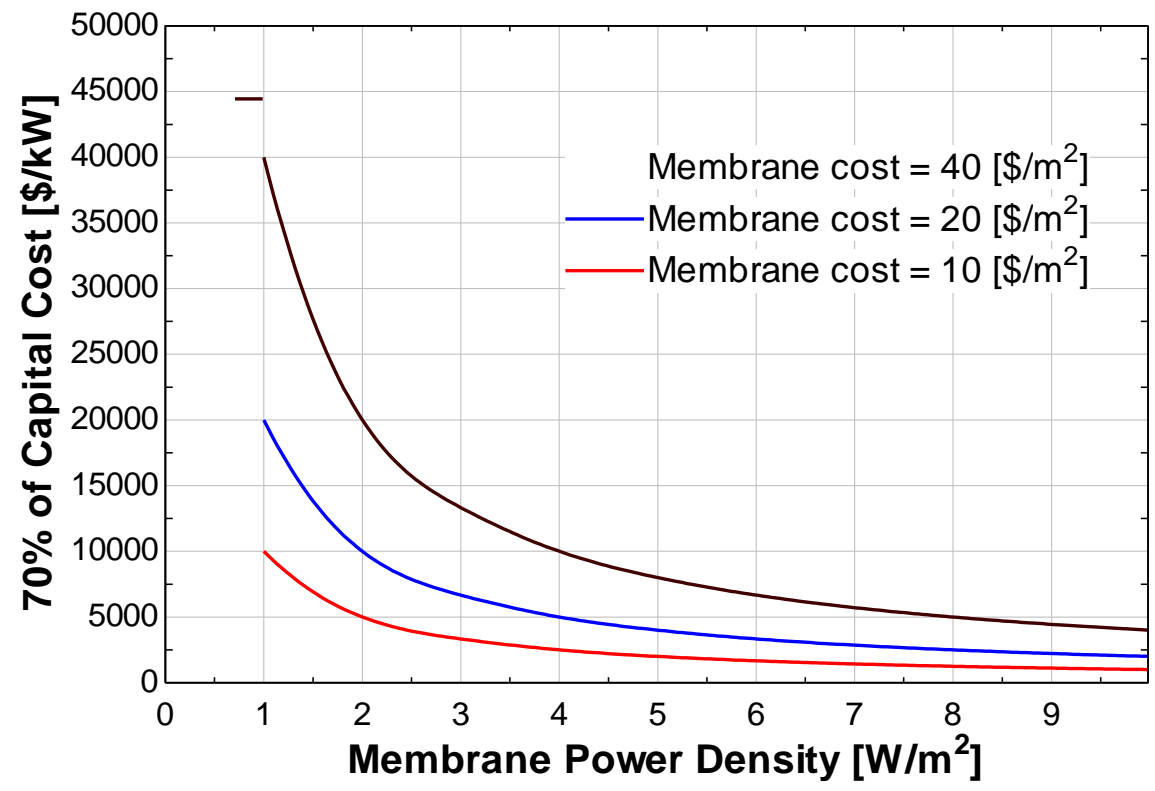

Fig. 3: The estimated capital cost per energy production for different membrane costs and power density.

\section{Conclusions}

Osmotic power production has a great potential in Ontario as a clean, stable and economically favorable source of renewable energy. Based on the findings of this study, Ontario rivers can generate an estimated technical power of $3.2 \mathrm{GW}$, considering available membrane performance and equipment efficiencies. On the other hand, the ecological power production is estimated to be $473.3 \mathrm{MW}$ considering only $15 \%$ of the river discharge. The total membrane cost is $\$ 2,000$ for each $\mathrm{kW}$ installed, which represents $70 \%$ of the capital cost based on a membrane price of $\$ 10$ per $\mathrm{m}^{2}$ and a power density of $5 \mathrm{~W} / \mathrm{m}^{2}$. The rapid development of the PRO membranes (similar to RO membranes) indicates that osmotic power will soon become more competitive than the current renewable energy sources (i.e. wind and solar). Prototype and pilot demonstration plants are supporting and accelerating the development of large-scale plants and commercialization.

\section{Acknowledgment}

The authors would like to thank the Natural Sciences and Engineering Research Council of Canada (NSERC-Grant \# 401366) for the funding support provided for this research.

\section{Nomenclature}

$\dot{m}$

$\dot{W}$

Greek symbols

$\eta$

$\theta$

$\pi$

$\rho$

Subscripts

$d$

$f$

in mass flow rate

power

combined turbine and generator efficiency

osmotic pressure ratio

osmotic pressure

density

draw solution

feed

inlet $\mathrm{kg} / \mathrm{s}$

$\mathrm{kW}$

$\mathrm{kPa}$

$\mathrm{kg} / \mathrm{m}^{3}$ 


\section{Reference}

[1] T. Y. Cath, A. E. Childress, and M. Elimelech, "Forward osmosis: Principles, applications, and recent developments," Journal of Membrane Science, vol. 281, no. 1-2. pp. 70-87, 15-Sep-2006.

[2] S. Loeb, "Large-scale power production by pressure-retarded osmosis, using river water and sea water passing through spiral modules," Desalination, vol. 143, no. 2, pp. 115-122, May 2002.

[3] K. Touati, F. Tadeo, S. H. Chae, J. H. Kim, and O. Alvarez-Silva, Pressure retarded osmosis : renewable energy generation and recovery. 2017.

[4] S. S. and S. S., "Reverse Osmosis-Pressure Retarded Osmosis hybrid system: Modelling, simulation and optimization," Desalination, vol. 389, pp. 78-97, Jul. 2016.

[5] F. Helfer, C. Lemckert, and Y. G. Anissimov, "Osmotic power with Pressure Retarded Osmosis: Theory, performance and trends - A review," J. Memb. Sci., vol. 453, pp. 337-358, 2014.

[6] S. Sarp, Z. Li, and J. Saththasivam, "Pressure Retarded Osmosis (PRO): Past experiences, current developments, and future prospects," Desalination, vol. 389, pp. 2-14, Jul. 2016.

[7] T. S. Chung, L. Luo, C. F. Wan, Y. Cui, and G. Amy, "What is next for forward osmosis (FO) and pressure retarded osmosis (PRO)," Sep. Purif. Technol., vol. 156, pp. 856-860, 2015.

[8] A. Bogler, S. Lin, and E. Bar-Zeev, "Biofouling of membrane distillation, forward osmosis and pressure retarded osmosis: Principles, impacts and future directions," J. Memb. Sci., vol. 542, no. May, pp. 378-398, 2017.

[9] A. Altaee and A. Sharif, "Pressure retarded osmosis: Advancement in the process applications for power generation and desalination," Desalination, vol. 356, pp. 31-46, 2015.

[10] P. Stenzel and H. Wagner, "Osmotic power plants: Potential analysis and site criteria," 3rd Int. Conf. Ocean Energy, pp. 1-5, 2010.

[11] T. Thorsen and T. Holt, "The potential for power production from salinity gradients by pressure retarded osmosis,"

Journal of Membrane Science, vol. 335, pp. 103-110, 2009.

[12] S. E. Skilhagen, "Osmotic power - a new, renewable energy source," Desalin. Water Treat., vol. 15, no. 1-3, pp. 271278, Mar. 2010.

[13] S.E.Skilhagen and R.J.Aaberg, "Power production based on the osmotic pressure difference between fresh water and seawater," in Proceedings of the European Seminar on Offshore Wind and Other Marine RenewableEnergies in

Mediterranean and EuropeanSeas (Owemes), Owemes, Citavecchia, Italy, 2006.

[14] C. B. Maisonneuve, J.; Pillay, P.; Laflamme, "Osmotic power potential in remote regions of Quebec," Renew. Energy, vol. 81, pp. 62-70, 2015.

[15] “Ontario Population Projections, 2018-2046, by Ontario Ministry of Finance," 2019.

[16] M. A.; C. A. C. ; M. Kazerani, "Renewable Energy Alternatives for Remote Communities in Northern Ontario, Canada," IEEE Trans. Sustain. Energy, vol. 4, no. 3, 2013.

[17] C. B. Laflamme, "Challenges facing osmotic power in Canada," in Presentation at the Integrated Network for Energy from Salinity Gradient Power symposium, Leeuwarden, Netherlands, 2013.

[18] L. D. Banchik, M. H. Sharqawy, and J. H. Lienhard, "Limits of power production due to finite membrane area in pressure retarded osmosis," J. Memb. Sci., vol. 468, pp. 81-89, 2014.

[19] K. G. Nayar, M. H. Sharqawy, L. D. Banchik, and J. H. Lienhard, "Thermophysical properties of sweater: A review and new correlations that include pressure dependence," Desalination, vol. 390, pp. 1-24, 2016.

[20] "https://www.canada.ca/en/environment-climate-change/services/water-overview/sources/rivers.html.".

[21] M. R. A., S. A. Akenhead;, and K. Drinkwater, "The influence of Hudson Bay runoff and ice-melt on the salinity of the inner Newfoundland Shelf," Atmosphere-Ocean, 1990.

[22] "OPG Annual Report by Ontario Power Generation,” 2017. 